\title{
Rubella in Europe
}

\author{
A. GALAZKA \\ Expanded Programme on Immunization, World Health Organization, \\ 1211 Geneva 27, Switzerland
}

\section{INTRODUCTION}

Postnatal rubella is a mild illness, a disease which was considered to be of only minor importance for many years. The first authors to write about the disease as distinct from other exanthemata were German physicians; they differentiated rubella from measles and scarlet fever in the latter part of the eighteenth century and called the disease Rotheln. Hence the common English language eponym is 'German measles'. Some consider that the term 'German' in German measles is probably of literary rather than of geographical significance and that it came from the old French 'germain' (derived from the Latin 'germanus'), meaning 'closely akin to' measles [1]. That it is not generally called by its German name, Rotheln, is due to Veale, a Scottish physician who in 1866 described 30 cases of rubella in the Edinburgh Medical Journal, and proposed 'rubella' as a short and euphonius name that could be easily pronounced [2].

Epidemics of rubella have been described in Europe and in the United States since the nineteenth century. A pandemic of rubella started in Europe in the early 1960s and it spread to the United States in the next several years. As a result, thousands of pregnancies were affected, leaving behind a wake of abnormal infants and terminated pregnancies [3]. The pandemic led to better understanding of the constellation of the disease caused by rubella infection during pregnancy. An expanded congenital rubella syndrome was recognized, adding to the already known rubella triad hepatitis, splenomegaly, thrombocytopenia, encephalitis, mental retardation and multiple other anomalies. The pandemic also made it obvious that a vaccine was urgently needed [4].

Between 1965 and 1967, several attenuated rubella strains were developed in the USA and rubella vaccine was introduced in the USA in 1969 and in the UK in 1970 .

\section{PLAN FOR ELIMINATION OF CONGENITAL RUBELLA SYNDROME IN EUROPE}

In 1984, the WHO Regional Committee for Europe set as one of the targets the elimination of congenital rubella from the Region by the year 2000. Other targets were elimination of indigenous measles, poliomyelitis, neonatal tetanus, and diphtheria. Recommendations on the work required to attain this target were put forward at the Second Conference on Immunization Policies in Europe, in Karlovy Vary, Czechoslovakia in December 1984 [5]. According to these recommendations, by 1990 all European countries should be using rubella vaccine in their national programmes, by 1995 all European countries should have achieved rubella vaccine 
coverage of at least $90 \%$ of the target population and established effective surveillance and investigation systems, and by 1996 all European countries should be investigating every suspected case of congenital rubella syndrome (CRS).

The current status of CRS elimination varies considerably in different European countries. Some countries have well-organized preventive programmes and others have no coherent policy for controlling rubella. If the goal of elimination of CRS from Europe by the year 2000 is to be achieved, it is vital that all countries in the Region strengthen their immunization programmes against rubella and set up effective surveillance systems.

\section{CURRENT STATUS OF RUBELLA}

Trends in incidence. Surveillance on the incidence of rubella and CRS was very poor in most European countries before 1985. It started to improve along with the introduction of MMR vaccine. At the beginning of the 1970s rubella was a notified disease in only eight European countries [6]. In 1990, rubella is a notifiable disease in 24 of 32 countries $(\mathbf{7 5} \%$ ) in the WHO European Region. Eight countries do not report rubella cases, including Germany and France. Congenital rubella syndrome is reported (separately from rubella) in only $13(41 \%)$ European countries [7]. The number of reported CRS cases ranged from 0 to 88 between 1985 and 1987 [8]. The completeness of the reporting of rubella in Europe is still low and the magnitude of under reporting is large. Although existing surveillance data cannot be considered qualitatively accurate, it is useful to depict the trends and patterns of rubella occurrence.

In the prevaccine era, minor epidemics of rubella occurred in the USA every 6-9 years; major epidemics occurred at intervals ranging from 10 to 30 years. Many European countries, however, reported a more frequent occurrence of rubella epidemics in the prevaccine era. Fairly intensive epidemics occurred at 4-year intervals in Czechoslovakia, Hungary, Poland and Yugoslavia. In the UK, the pattern was more irregular, with an interval of 8-9 years between major epidemics and with less regular epidemics in the intervening years [9]. Epidemic waves continue to be reported every 4-5 years in countries which did not implement routine rubella immunization programmes in young children (Fig. 1a). The epidemics built up and receded over 3 to 4 -year intervals. In countries, that implemented routine rubella immunization programmes for young children, a downward trend in rubella incidence is clearly seen after 1985 (Fig. 1b).

\section{Age distribution of immunity against rubella}

Because a significant proportion of rubella infection is subclinical, serological surveys are essential in further delineating the epidemiology of rubella. The rubella antibody profile of a population is related to age-specific rubella incidence. Before the introduction of rubella vaccine in European countries, the percentage of immune individuals increased steadily with age; approximately $50 \%$ of children had rubella antibody by the age of 6-8 years (Fig. 2). More than $80 \%$ of population had rubella antibody by 17-22 years and the percentage remained relatively stable thereafter [13-20]. It should be stressed that from 5 to $20 \%$ of persons between 15 and 35 years of age remain seronegative and susceptible to 

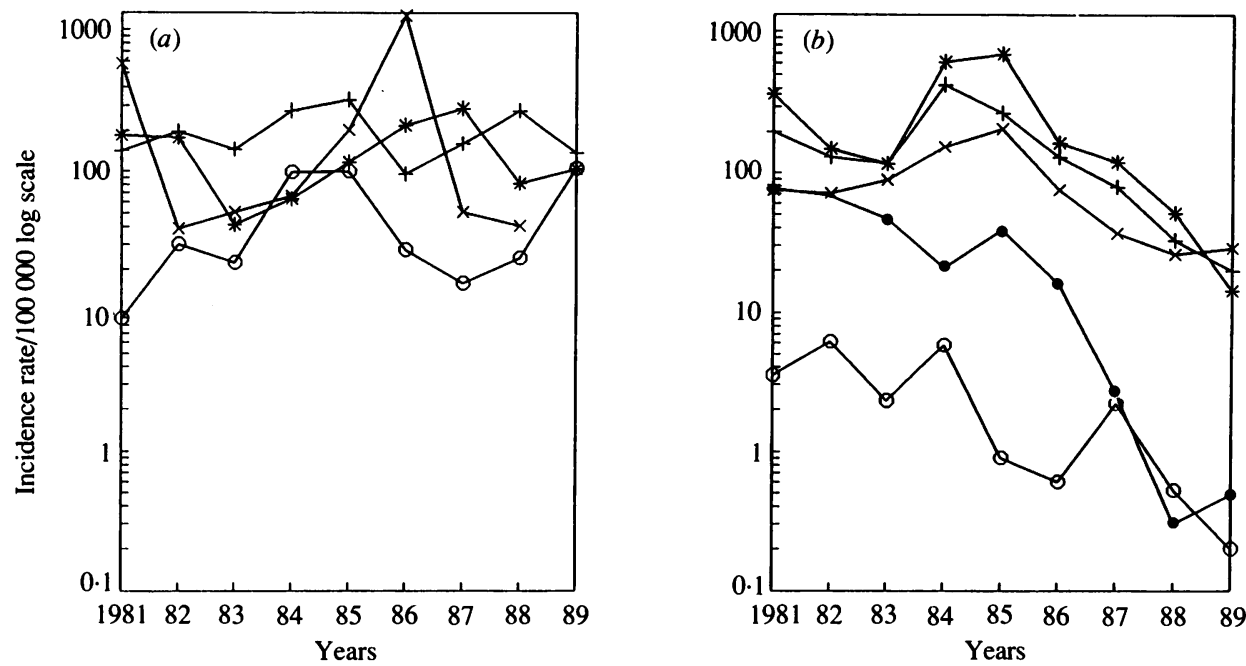

Fig. 1. Reported rubella incidence per 100000 population in several European countries, 1981-9. (a) Countries with no routine immunization against rubella in young children: +-+ , Romania; $\times-\times$, Poland; * * Bulgaria; $\mathrm{O}-\mathrm{O}$, Italy. (b) Countries with routine immunization against rubella in young children: $\bullet-\bullet$, Finland; +-+, Denmark; * * Czechoslovakia; $\mathrm{O}-\mathrm{O}$, The Netherlands; $x-x$, Norway.
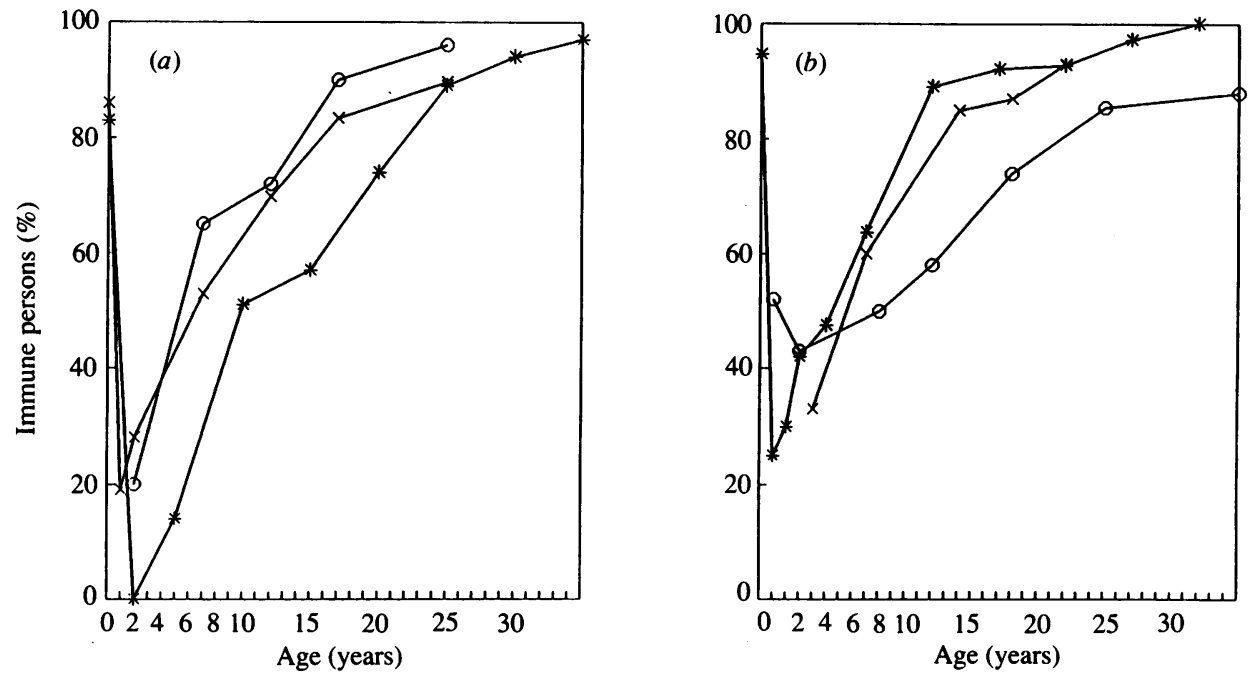

Fig. 2. Percentage of sera with antibodies against rubella by age groups in several European countries, 1965-83 (according to Kantoch \& Imbs [10], Lundstrom and colleagues [11], Mihneva and colleagues [12], Toth [13] and WHO [9]). (a) O- $\bigcirc$, USSR 1971; $X-X$, Germany 1971; * *, Sweden 1965 (females). (b) * * Poland 1982 (females); $\times-\times$, Bulgaria 1971-83 (females); $\bigcirc-O$, Hungary 1967.

infection. In some countries (Poland, Bulgaria), the rate that immunity to rubella was acquired seemed more rapid than in other countries (Hungary, Sweden) (Fig. 2, Table 1). In the USSR, the immunity status varied in different areas; the development of more than $85 \%$ level of immunity against rubella was completed by 18-22 years in Moscow, by 13-14 years in the Armenian and Georgian republics 

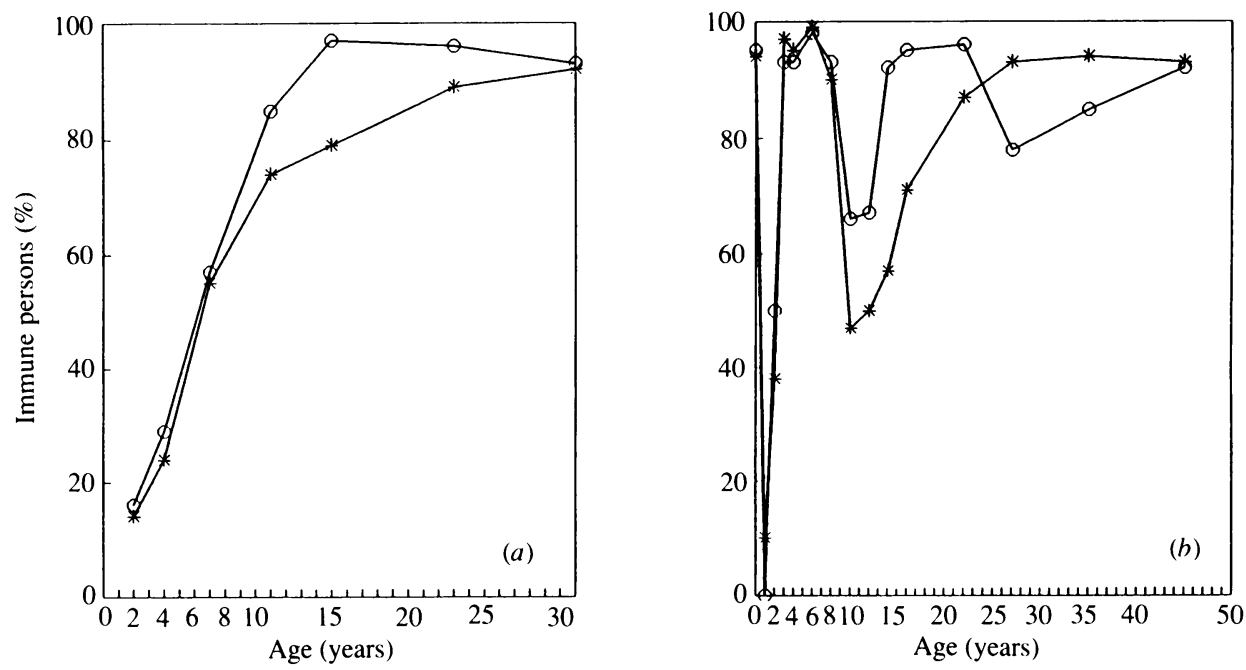

Fig. 3. Percentage of sera with antibodies against rubella in England, 1988 and in Finland, 1986 (according to Morgan-Capner and colleagues [25] and Ukkonen and colleagues [20]). (a) England 1988: $\bigcirc-\bigcirc$, females; * * males. (b) Finland 1986: $\mathrm{O}-\mathrm{O}$, females; * * males.

and by 10 years in the Kirghiz republic [24]. Within a particular country, the pattern of rubella immunity appears to be stable over a long period of time (Poland 1969 and 1982, Table 1). Rubella immunity has been found to be acquired more slowly than immunity against measles, mumps and Epstein-Barr virus $[25,26]$.

The introduction of rubella vaccine significantly changed the pattern of immunity. In the UK, where rubella vaccine was used in prepubertal girls and non-immune women, the proportions of subjects who have rubella antibody were significantly higher in females than in males in age groups between 10 and 30, reflecting the effect of selective rubella vaccination of girls and women (Fig. 3). The effect of vaccination of 13-year-old girls is also seen in Finland when the immunity against males and females is analyzed separately (Fig. 3).

The vaccination of children with MMR vaccine resulted in a significant increase of rubella immunity among children. In Finland, before the introduction of MMR vaccine, the percentage of immune individuals increased steadily, reaching a plateau level of $90 \%$ by 17 years. MMR vaccine was introduced in 1982, and in 1986 about $95 \%$ immunity was achieved by the age of $2-3$ years (Figs. 3,4 ).

\section{Age distribution of infection}

The age specific infection pattern of rubella in the prevaccine era was quite distinct from that of measles. Whereas measles infection rates were highest during the first several years of life and decline to a negligible level by age 15, rubella infection rates reached a peak later and continued through adolescence into young adulthood [3].

In the prevaccine era, rubella was a childhood disease with the highest incidence rates in the 5-14 years age group. Incidence rates increased slowly among children of age 0-4 years, rose more steeply among children age 5-14 years, and then slowly 

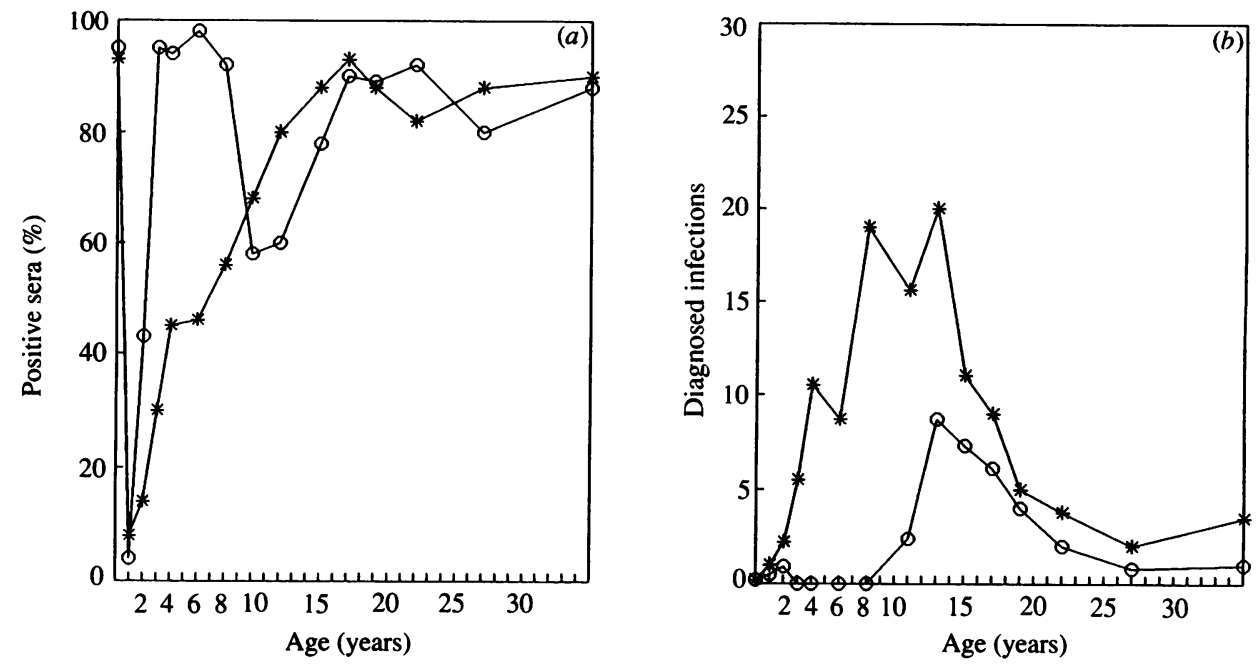

Fig. 4. Occurrence of rubella IgG antibodies in sera and rubella infections in different age groups, Finland 1980 and 1986 (according to Ukkonen and colleagues [20]). (a) Rubella antibodies: * * 1980 ; $\bigcirc-O, 1986$. (b) Rubella infections: * * 1980 ; O-O, 1986.

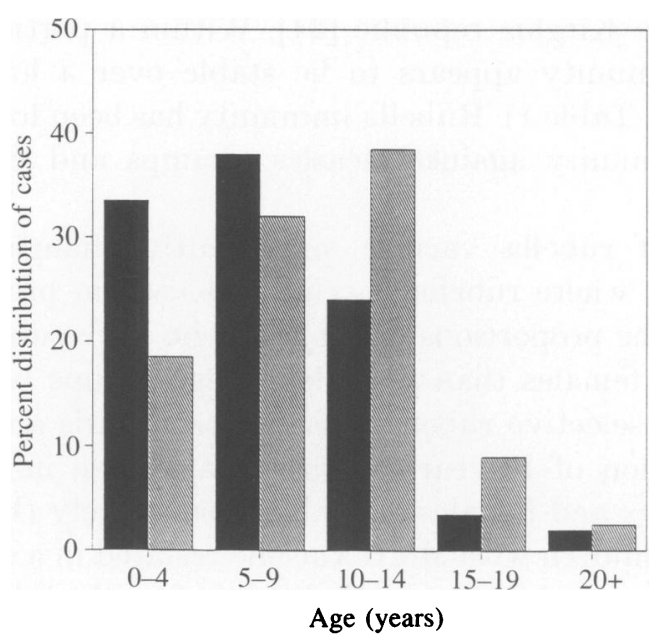

Fig. 5. Percentage distribution of rubella cases reported in 84 selected districts by age groups and urban-rural status, Poland, 1967-74 (according to Rudnicka [27]). Urban areas; $\mathbb{\mathbb { N }}$, rural areas.

decreased. A similar pattern was observed in Finland before the introduction of MMR vaccination in young children (Fig. 4). The age-specific pattern of rubella incidence differed between urban and rural areas. Data from Poland showed that the highest rate in urban areas was reported for 5- to 9-year-old children, while in rural areas the highest rate was shifted to the 10-14 years age group [27] (Fig. 5).

There is some evidence to suggest that the age-specific pattern of rubella is changing in countries which have implemented routine immunization schedules for children. In Finland, after the introduction of MMR vaccine in 1982 among children of 14-18 months and 6 years old, the occurrence of rubella cases shifted 
to higher ages, peaking between 12 and 17 years of age. In 1986, no rubella cases were found in children covered by MMR vaccination in the 2-10 years age group (Fig. 4). The changes in incidence were correlated with the changes in the agespecific immunity [20].

\section{VACCINATION AGAINST RUBELLA}

\section{Strategies for vaccination}

The primary aim of rubella immunization is to prevent congenital rubella syndrome. Congenital rubella is a preventable disease provided vaccination programmes are carefully planned and implemented. There are three main approaches which have been applied in the USA, the UK and Sweden (Table 2).

The first approach has been used in the USA. This approach starts with mass vaccination of children under the age of 12 years and is followed by routine vaccination of children of both sexes when they reach one year of age. This approach is intended to interrupt transmission of rubella virus among young children (the primary transmission group), thus reducing the possibility of exposure of a susceptible pregnant woman [29]. This strategy requires a high immunization coverage of children at 15 months of age with combined MMR vaccine. The attainment of very high levels of vaccination coverage in pre-school children $(>90 \%)$ is, in part, a consequence of the USA school immunization law, which require documentary evidence of immunization against certain common vaccine-preventable diseases prior to school entry.

The second approach was undertaken until 1988 in the United Kingdom, and is used in some European countries. This approach is a selective policy to vaccinate prepubertal girls and non-immune women either before or after pregnancy with one dose of monovalent rubella vaccine. This strategy aims to protect individuals, but not to diminish the natural circulation of the wild virus. Neither the reduction of natural rubella, nor the development of herd immunity is part of the strategy; indeed the continued circulation of rubella virus was considered a necessary contribution to maintaining the level of immunity in women of child-bearing age [30].

The third approach has been implemented in Sweden. In 1980, the Swedish Paediatric Association recommended a two-dose schedule using a combined MMR vaccine and the programme was introduced in January 1982. Vaccination is optional and is offered free of charge to children at 18 months (at child health centres) and at 12 years (at school health centres). The ultimate aim of this approach is the elimination of rubella as well as measles and mumps. The second dose is given irrespective of history of disease or vaccination. This serves to prevent the build-up of a susceptible population in older age-groups [31]. It is expected that the second dose of MMR will immunize those not vaccinated at 18 months and those who failed to respond to the first dose of vaccine; it will also provide a booster for children with low antibody titres [32].

The programme appears to have been successfully implemented; in $1985 \mathrm{MMR}$ coverage of preschool children and 12-year-old children in Sweden was about $90 \%$ [33]. Continuous studies on epidemiology and immunity against three diseases will be necessary to assess the effectiveness of this approach. 
Table 2. Comparison of three vaccination programmes to prevent congenital rubella (according to Dudgeon, 1983 [28])

\begin{tabular}{|c|c|c|c|}
\hline $\begin{array}{l}\text { Prototype } \\
\text { country }\end{array}$ & Objective & Vaccine schedule & Target groups \\
\hline USA & $\begin{array}{l}\text { Break in transmission: } \\
\text { control of reservoir and } \\
\text { eradication of disease }\end{array}$ & One dose of MMR & $\begin{array}{l}(a) \text { all children } \\
\text { at } 15 \text { months } \\
(b) \text { adolescent and } \\
\text { adult 'susceptible } \\
\text { females } \\
(c) \text { educational and } \\
\text { health care } \\
\text { personnel }\end{array}$ \\
\hline UK & $\begin{array}{l}\text { Selective immunization } \\
\text { Protection of the } \\
\text { individual }\end{array}$ & $\begin{array}{l}\text { One dose of mono- } \\
\text { valent rubella } \\
\text { vaccine }\end{array}$ & $\begin{array}{l}(a) \text { all girls at } 10- \\
14 \text { years } \\
(b) \text { 'susceptible' } \\
\text { females } \\
(c) \text { educational and } \\
\text { health personnel } \\
\text { (d) postpartum } \\
\text { women }\end{array}$ \\
\hline Sweden & $\begin{array}{l}\text { Eradication of rubella } \\
\text { in } 10 \text { years }\end{array}$ & Two doses of MMR & $\begin{array}{l}(a) \text { all children at } \\
18 \text { months } \\
(b) \text { all children at } \\
12 \text { years }\end{array}$ \\
\hline
\end{tabular}

Finland introduced a two-dose MMR schedule in November 1982 with doses given to children at 14-18 months and 6 years [20]. Norway adopted two-dose MMR schedule in 1983.

\section{Immunization schedules used in Europe}

There are three main immunization schedules used in European countries in 1990 (Table 3). Five countries (Denmark, Finland, the Netherlands, Norway and Sweden) use the Swedish approach vaccinating children at a young age and again at school age.

A second group of countries uses an approach combining both mass immunization of young children and selective vaccination of girls at a later age. A combined measles, mumps and rubella (MMR) vaccine is used for young children and for older children in the first approach, and monovalent rubella vaccine is used for selective vaccination of girls.

A third group of countries uses 'selective' vaccination of teenage girls without MMR for young children.

The USSR has already decided to introduce immunization against rubella but the implementation of the programme is delayed by the lack of the vaccine which is not yet locally produced. Albania, Bulgaria and Romania would also like to use MMR vaccine when available.

\section{Choice of the strategy}

Choice of the appropriate policy in any country should take into consideration the age distribution of immunity and infection and administrative, regulatory, or educational feasibility of achieving and sustaining a high vaccine coverage. 
Table 3. Schedules for rubella vaccination currently used in some European countries (according to Mata and Wals [34] and Miller and Salisbury [35])

Vaccination schedule for

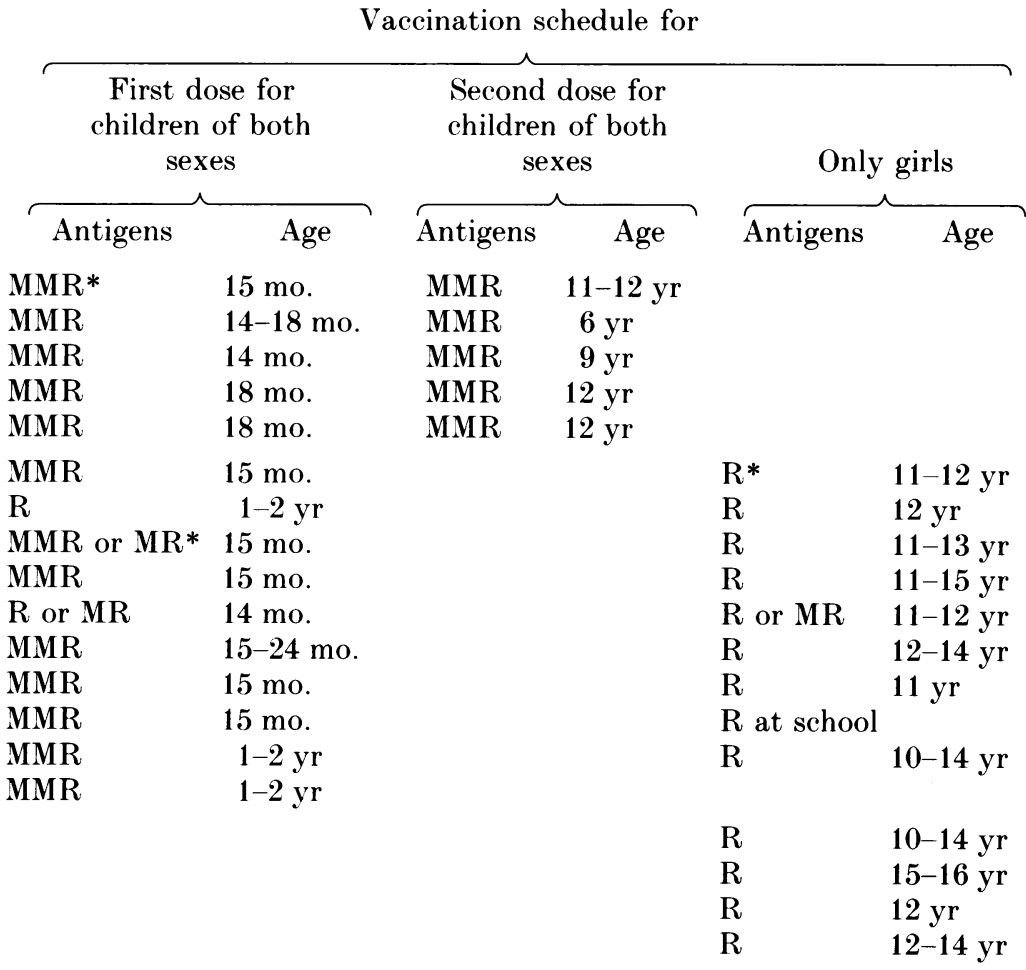

* MMR, measles, mumps and rubella combined vaccine; MR, measles and rubella combined vaccine; $R$, monovalent rubella vaccine.

Selective rubella vaccination has achieved a substantial reduction in incidence of rubella infection in pregnancy and its inevitable sequelae of congenital rubella syndrome. However, recent epidemiological evidence has shown that while rubella virus continues to circulate among children there is the risk of infection to pregnant women, even when only $3 \%$ of them are non-immune. The number of infections among the $2-3 \%$ of pregnant women still susceptible remains unacceptably high and there is no prospect of eliminating congenital rubella syndrome with selective vaccination alone $[30,36]$. Therefore, a selective strategy has been gradually abandoned in favour of combined strategies that include mass immunization of young children in addition to immunization of schoolgirls and susceptible females. Such a strategy has been endorsed by the recent meeting of national programme managers on the WHO Expanded Programme on Immunization in St Vincent in Italy [37].

The introduction of mass immunization of young children against rubella quickly reduces the circulation of rubella virus. This postpones the age of first exposure among the unvaccinated to early adult life. These hazards are more intrusive when vaccination is performed early and when children of both sexes are vaccinated [38]. Replacing single-antigen measles vaccine with the triple-antigen MMR vaccine in a large proportion of children $(80 \%$ or more) will rapidly reduce 
the circulation of rubella and thus the chance of infection of non-immune pregnant women. However, it has been postulated, using predictions from mathematical models, that if MMR vaccine coverage is less than $60-70 \%$, infection in persons who remain unvaccinated may be deferred until adult life; in the case of rubella it has been suggested that this could result in a possible increase in congenital rubella syndrome [39]. Thus, an inadequately implemented childhood rubella immunization policy could cause more damage than no rubella vaccination at all [35]. In many European countries, the coverage with measles vaccine is still low and it is important that coverage is increased before or when introducing MMR vaccine. Several approaches have been suggested including introduction of legislation requiring evidence of immunization for entry to school, increased professional commitment toward vaccination and providing adequate funding for local staff and adequate amounts of vaccine [30].

\section{Monitoring the rubella control programme}

It is important that any rubella control programme has built in monitoring systems. Vaccine coverage of target age-groups should be monitored. MMR vaccine has been introduced into the routine immunization schedules in 19 European countries. Data on vaccine coverage are incomplete but from the information reported to the $\mathrm{WHO}$, one may conclude that coverage rate of at least $80 \%$ in young children has been achieved in nine countries. Two countries reported the coverage rate around $60 \%$ and data from the remaining eight countries are not yet available $[7,40]$.

Surveillance systems should be developed and strengthened to monitor the impact of the immunization programme. Countries without rubella control programmes should assess the magnitude of congenital rubella infection by estimating the frequency of rubella infections in pregnant women or by determining by serosurveys the susceptibility and/or age-specific acquisition of rubella antibody in postpubertal women. Countries with rubella control programmes should monitor cases of acquired rubella, including CRS, and prevalence of seropositivity in postpubertal females. Surveillance systems should include monitoring rubella associated termination of pregnancies and investigation of deafness in childhood. This will help to assess the effectiveness of the programme and to determine high risk populations that should be targets of intensified vaccination efforts [41]. In countries using MMR vaccine, measles, mumps and rubella should all be notifiable diseases.

\section{REFERENCES}

1. Christie AB. Infectious diseases. Epidemiology and clinical practice, 4th ed. vol. 1. Edinburgh: (Churchill Livingstone 1987: 581-2.

2. Horstman DM. Rubella. In: Evans AS, ed. Viral infections of humans. Epidemiology and control, 2nd ed. New York and London; Plenum Medical Book Company 1983 : 519-39.

3. Witte JJ, Karchmer AW, Case G, et al. Epidemiology of rubella. Amer J Dis Child 1989; 118: $107-11$.

4. Plotkin SA. Rubella vaccine. In: Plotkin SA, Mortimer EA, eds. Vaccines. Philadelphia, London, Toronto, Montreal, Sydney, Tokyo: Saunders Company 1988: 235-62.

5. Expanded Programme on Immunization. European conference on immunization policies. Wkly Epidemiol Rec 1985; 60 : 165-8. 
6. Krohn EF. Epidemiological aspects of rubella in Europe. Int J Epidemiol 1972; 1 : 267-70.

7. Bytchenko B. EPI overview in European Region. Presented at the 13th Meeting of the Expanded Programme on Immunization Global Advisory Group, 14-18 October 1990, Cairo, Egypt, WHO Document EPI/GAG/90/WP.5.

8. Salisbury DM. Elimination of congenital rubella. Presented at the Second Meeting of National Programme Managers on Expanded Programme on Immunization, Istanbul, 23-26 May 1989, WHO Regional Office for Europe, Document ICP/EPI 021/8, 9 May 1989.

9. World Health Organization. Prevention of rubella. Report on a Working Group, Budapest 12-16 June 1972. WHO Regional Office for Europe, Copenhagen 1973.

10. Kantoch M, Imbs D. Postinfection and postvaccination antirubella immunity. Acta Virol $1986 ; 30: 381-9$.

11. Lundstrom R, Svedmyr A, Hagbard L, Kaijser K. Rubella immunity as related to age and history of overt diseases. Acta Paediatr Scand 1967; 56 : 279-85.

12. Mihneva $Z$, Odiseev $H$, Katev $P$, et al. Immune status with respect to rubella infection in women of child bearing age in Bulgaria. Epidemiol Mikrobiol Infect Bol 1985; 22: 9-14.

13. Toth M. Incidence of rubella virus neutralizing antibody in different age groups. Acta Microbiol Acad Sci Hung 1968; 15 : 119-24.

14. Assaad F, Ljungars-Esteves K. Rubella - world impact. Rev Infect Dis 1985; 7, Suppl. 1 : S29-36.

15. Cockburn WC. World aspects of the epidemiology of rubella. Amer J Dis Child $1969 ; 118$ : 112-22.

16. Kantoch M, Fidzianska E, Ziembinski W, et al. Antibodies against rubella virus in selected regions of Poland. Exper Med Microbiol 1971; 23 : 639-44.

17. Leerhoj J. Neutralizing antibody to rubella virus in sera collected in Denmark. Danish Med Bull 1968; 15 : 273-6.

18. Majer R. Epidemiologische Untersuchungen und Erfarhrungen mit einem attenuierten Impfstoff ('Cendehill strain'). Helv Paediatr Acta 1967; 6: 579-90.

19. Rawls WE, Melnick JL, Bradstreet CMP, et al. WHO collaborative study on the seroepidemiology of rubella. Bull WHO $1967 ; 37: 79-88$.

20. Ukkonen $\mathrm{P}$, von Bonsdorf C-H. Rubella immunity and morbidity : effects of vaccination in Finland. Scand J Infect Dis 1988; $20: 255-9$.

21. Iorio AM, Rivosecchi P, Fanelli M, Pitzurra M. Distribuzione degli anticorpi contro il virus della rosolia in un camione di popolazione femminile del comune di Perugia a resultati sierologici di un esperimento di vaccinazione antirosolia. Boll Ist Sieroterap Milan 1972; 51 : $405-9$.

22. Enders-Ruckle G. Seroepidemiology of rubella and reinfection. Amer J Dis Child 1969; 118 : 139-42.

23. Imbs D, Rudnicka H, Diuwe A. Seroepidemiological investigations on rubella in Polish population. Przegl Epidemiol 1985; 39: 193-8.

24. Andzhaparidze OG, Desyatskova RG, Chervonsky GI, et al. Seroepidemiology of rubella in the USSR. Vop Virusol 1972; $4: 412-8$.

25. Morgan-Capner P, Wright J, Miller CL, Miller E. Surveillance of antibody to measles, mumps and rubella by age. Brit Med J 1988; 297 : 770-2.

26. Svedmyr A. Acquisition and decline of rubella immunity. Problem of reinfections. Amer J Dis Child $1969 ; 118$ : $137-8$.

27. Rudnicka H. Rubella epidemiology in Poland. Przegl Epidemiol 1977; 31 : 261-74.

28. Dudgeon JA. Immunization against rubella. Intern Planned Parenthood Fed Med Bull $1983 ; 17: 2-4$.

29. Hinman AR, Bart KJ, Orenstein WA, Preblud SR. Rational strategy for rubella vaccination. Lancet 1983 ; i : $39-41$.

30. Miller E. Measles, mumps and rubella: Present and future immunisation policy. Publ Hlth $1988 ; 102: 317-21$.

31. Bottiger M, Christenson B, Taranger J. Bergman M. Mass vaccination programme aimed at eradicating measles, mumps and rubella in Sweden : vaccination of schoolchildren. Vaccine $1985 ; 3: 113-6$.

32. Rabo E, Taranger J. Scandinavian model for eliminating measles, mumps, and rubella. Brit Med J 1984; 289: 1402-4.

33. Bottiger M, Christenson B, Romanus V, Taranger J, Strandell A. Swedish experience of two 
dose vaccination programme aiming at eliminating measles, mumps, and rubella. Brit Med J 1987 ; 295 : $1264-7$.

34. De la Mata I, de Wals P. Policies for immunization against rubella in European countries. Eur J Epidemiol 1988; 4: 175-80.

35. Miller C, Salisbury DM. Elimination of the congenital rubella syndrome. Third Meeting of National Programme Managers on Expanded Programme on Immunization, St Vincent, Italy, 22-25 May 1990. WHO Regional Office for Europe, Document ICP/EPI 023/13, 17 May 1990.

36. Miller CL, Miller E, Sequeira PJL, et al. Effect of selective vaccination on rubella susceptibility and infection in pregnancy. Brit Med J 1985; 291 : 1398-1401.

37. World Health Organization. Third Meeting of National Programme Managers on the Expanded Programme on Immunization. Report on a WHO Meeting, St Vincent, Italy, 22-25 May 1990. WHO Regional Office for Europe, Copenhagen, EUR/ICP/EPI 023, 1990.

38. Knox EG. Theoretical aspects of rubella vaccination strategies. Rev Infect Dis 1985; 7, Suppl. 1 : S194-7.

39. Anderson RM, May RM. Two-stage vaccination programme against rubella. Lancet 1983; ii : $1416-7$.

40. Bytchenko B. Expanded Programme on Immunization in the European Region. Progress Report. Third European Meeting of the National Programme Managers on the Expanded Programme on Immunization, St Vincent, Italy, 22-25 May 1990. WHO Regional Office for Europe, Document ICP/EPI/023/11, 16 May 1990.

41. Orenstein WA, Preblud SR, Bart KJ, Hinman AR. Methods of assessing the impact of congenital rubella infection. Rev Infect Dis 1985; 7, Suppl. 1: S22-8. 